\title{
Atuação do enfermeiro frente a mulher vítima de violência sexual
}

\author{
Nurse's performance towards women victims of sexual violence
}

Actuación de enfermeras frente a mujeres víctimas de violencia sexual

Jessika Bruna de Souza Rodrigues ${ }^{1}$, Lucineide Rodrigues de Lima Filha ${ }^{1 \star}$, Yanca Seixas da Costa ${ }^{1}$, Jeosafá de Souza Santos ${ }^{1}$, Michael Ramos da Silva ${ }^{1}$, Martulon Araújo Brandão ${ }^{1}$, Lorena Vitória Silva Santos ${ }^{1}$, Vanda Corrêa de Souza ${ }^{1}$, Joianny Santana Cabo Verde ${ }^{1}$, Graciana de Sousa Lopes ${ }^{1}$.

\section{RESUMO}

Objetivo: Revisar e analisar o papel do enfermeiro no contexto da mulher vítima de violência sexual. Métodos: Trata-se de uma pesquisa descritiva, exploratória, de cunho qualitativo do tipo revisão integrativa de literatura, realizada através das bases de dados da Biblioteca Virtual em Saúde (BVS) e Scientific Electronic Library Online (Scielo), Diadorim e Latindex. Resultados: A violência sexual contra a mulher é um problema universal e fortemente presente no Brasil, está intimamente ligada as desigualdades nas relações de gênero, que impacta fortemente a qualidade de vida das vítimas devido os danos físicos e psicológicos. $O$ enfermeiro lida com diversas dificuldades para prestar uma assistência adequada as vítimas, como ausência de protocolos de cuidados, estruturas inadequadas, dentre outras problemáticas. Considerações finais: $O$ cuidado de enfermagem à mulher vítima de violência sexual, apresenta-se com atitudes acolhedoras e humanizadas, podendo ser melhorado, a partir de articulações intersetoriais que visem a prevenção, o tratamento e a notificação adequada dos casos.

Palavras-chave: Saúde da mulher, Violência contra a mulher, Delitos sexuais, Cuidado de enfermagem.

\begin{abstract}
Objective: Review and analyze the role of nurses in the context of women who are victims of sexual violence. Methods: It is a descriptive, exploratory, qualitative research of the type integrative literature review, carried out through the databases of the Virtual Health Library (VHL) and Scientific Electronic Library Online (Scielo), Diadorim and Latindex. The articles were selected according to eligibility and ineligibility criteria. Results: Sexual violence against women is a universal problem and strongly present in Brazil, it is closely linked to inequalities in gender relations, which strongly impacts the quality of life of victims due to physical and psychological damage. The nurse deals with several difficulties to provide adequate assistance to the victims, such as the absence of care protocols, inadequate structures, among other problems. Final considerations: Nursing care for women victims of sexual violence, presents itself with welcoming and humanized attitudes, which can be improved, based on intersectoral articulations aimed at prevention, treatment and adequate notification of cases.
\end{abstract}

Keywords: Women's health, Violence against women, Sexual offenses, Nursing care.

\section{RESUMEN}

Objetivo: Este artículo buscó revisar y analizar el rol de las enfermeras en el contexto de las mujeres víctimas de violencia sexual. Métodos: Se trata de una investigación descriptiva, exploratoria, cualitativa del tipo revisión integradora de la literatura, realizada a través de las bases de datos de la Biblioteca Virtual en Salud (BVS) y Biblioteca Científica Electrónica en Línea (Scielo), Diadorim y Latindex. Los artículos fueron seleccionados según criterios de elegibilidad e inelegibilidad. Resultados: La violencia sexual contra las

${ }^{1}$ Centro Universitário Fametro (CEUNI-FAMETRO), Manaus - AM. *E-mail: lucy_filha@outlook.com 
mujeres es un problema universal y fuertemente presente en Brasil, está íntimamente ligada a las desigualdades en las relaciones de género, lo que impacta fuertemente en la calidad de vida de las víctimas por daño físico y psicológico. La enfermera enfrenta varias dificultades para brindar una adecuada asistencia a las víctimas, como la ausencia de protocolos de atención, estructuras inadecuadas, entre otros problemas. Consideraciones finales: La atención de enfermería a las mujeres víctimas de violencia sexual se presenta con actitudes acogedoras y humanizadas, que pueden mejorarse, a partir de articulaciones intersectoriales orientadas a la prevención, tratamiento y adecuada notificación de los casos.

Palabras clave: Salud de la mujer, Violencia contra la mujer, Delitos sexuales, Cuidados de enfermería.

\section{INTRODUÇÃO}

O cuidado, essência da enfermagem enquanto ciência e profissão, baseia-se em uma atitude multifacetada, que compreende zelo, desvelo, atitude, solicitude que se concretiza na vida de sujeitos humanos e de sociedades. Por tratar-se de um processo inerente a uma ciência, o cuidado da enfermagem torna-se dinâmico e tende a modificar-se, de acordo com a evolução das concepções humanas sobre o ser cuidado, bem como pelos próprios problemas que se apresentam no mundo e nas relações e que demandam esta ação concreta da enfermagem (SOUZA ML, et al., 2005; MORAES SCRV, et al., 2010).

Dentre as populações destaque no que diz respeito à recepção do cuidado de enfermagem estão as mulheres vítimas da violência, tida como importante problema de saúde pública, de forma mais específica, àquelas vítimas da violência sexual. $O$ número de mulheres violentadas sexualmente tem aumentando em vários países no mundo e, por essa razão tem despertado o olhar de governos, instituições, universidades, sociedade e estudiosos, como importante fenômeno a ser urgentemente desvelado e problematizado (MORAES SCRV, et al., 2010; CECCON RF e MENEGHEL SN, 2017).

No contexto da violência sexual, mulheres tem recebido especial atenção de profissionais e estudiosos desta problemática, visto que são as mais propensas a este tipo de violação, que por muitos séculos foi mascarada e silenciada, tendo como ancoragem a garantia de inviolabilidade do mundo privado (SOUZA CS, 2012).

A este respeito Lima CA e Deslandes SF (2014), constataram que o fenômeno da violência sexual é mais prevalente em mulheres jovens e adultas, fato este que se explica pelas próprias relações assimétricas de gênero e pelas sujeições de poder onde o mais velho, neste caso o homem, exerce sobre o mais novo, a mulher (MATOS M, 2008; MACHADO CL, et al., 2015; NUNES MCA, et al., 2017).

Este cenário é fruto de uma construção histórico-social onde mulheres são oprimidas em relação aos homens, considerando também o contextos e tempos diferentes da condição humana que tornam as mulheres mais vulneráveis aos homens no que tange à sexualidade e as violências que perpassam neste meio (MATOS M, 2008; MACHADO CL, et al., 2015; NUNES MCA, et al., 2017).

Neste sentido, a violência sexual contra mulheres pode ser caracterizada como grave problema social e de saúde pública, ainda subnotificado e, que resulta em acréscimo aos índices de morbimortalidade feminina. Verifica-se ainda que a violência sexual pode acarretar inúmeras consequências para a mulher, como estresse pós-traumático, somatizações, tentativas de suicídio e quadro depressivos; além de vulnerabilizar as mesmas com infecções sexualmente transmissíveis e à gravidez indesejada (REIS MJ, et al., 2010a; MACHADO CL, et al., 2015; NUNES MCA, et al., 2017).

Apesar de remontar séculos, a violência sexual contra a mulher se mantem atual e colabora diretamente para fragilização da qualidade de vida e saúde desse seguimento da população em todo o mundo, em especial no Brasil. Dados do Anuário de Segurança Pública de 2014 revelam que houveram 47.646 casos de estupro no Brasil, com uma taxa de subnotificação em torno de 35\%, com uma correção é possível que se tenha cerca de 500 casos de violência sexual por dia (GARCIA LP, 2016). 
Além disso, $90 \%$ das brasileiras relataram ter medo de serem agredidas sexualmente, relatos estes que vão ao encontro as estatísticas sobre violência contra a mulher no país, onde o risco de uma mulher ser agredida sexualmente semelhante ao risco de um homem ser assassinado por arma de fogo e cerca de 12 vezes maior ao risco de contrair um infecção pelo vírus da Zika, evidenciando que este problema toma dimensões epidêmicas em território nacional, apesar de sua invisibilidade quando analisado do ponto de vista da subnotificação (LIMA CA e DESLANDES SF, 2014; GARCIA LP, 2016).

Desde a década de 80, o Ministério da Saúde (MS) vem introduzindo no Brasil políticas públicas que busquem dar respostas efetivas no sentido de procurar garantir os direitos sexuais e reprodutivos das mulheres brasileiras (BRASIL, 2012; LIMA CA e DESLANDES SF, 2014; NUNES MCA, et al., 2017).

Inicialmente, isto se deu no contexto da Política Nacional de Atenção Integral à Saúde da Mulher (PNAISM) e, posteriormente, por meio de Nota Técnica que instituiu o atendimento multidisciplinar às mulheres vítimas de violência sexual no país (BRASIL, 2012; LIMA CA e DESLANDES SF, 2014; NUNES MCA, et al., 2017).

Entretanto, apesar do estabelecimento de diretrizes ministeriais para atendimento às mulheres em cenários de violência sexual, estudos têm mostrado que várias são as barreiras que dificultam o enfrentamento desta problemática, incluindo o posicionamento dos profissionais de saúde, incluindo de enfermagem, muitas vezes, permeado pelo medo e desconhecimento de como essas situações afetam a vida das mulheres na sociedade, assim como esse fenômeno pode impactar na vida dessas, de suas famílias e de toda a sociedade (SILVA LMP, et al., 2011; SOUZA CS, 2012; LIMA CA e DESLANDES SF, 2014).

Além disso que a compreensão sobre o fenômeno da violência sexual contra a mulher e suas múltiplas facetas constitui importante estratégia para que os profissionais de enfermagem possam modelar o seu atendimento a esta população neste contexto de vulnerabilidade social, constituindo assim, imprescindível ferramenta para enfermeiros nas suas práxis cuidativas (REIS MJ, et al., 2010a).

Dessa forma, faz-se necessário que se coloque em pauta a necessidade de aprimoramento teóricoconceitual das máximas que envolvem a violência sexual contra a mulher, sua complexidade nos diferentes contextos nos quais a mesma se apresenta, suas tipologias e as formas como o enfermeiro pode atuar no sentido de compreender e buscar caminhos que ajudem as vítimas a enfrentarem esta problemática. De acordo com as problemáticas expostas, questiona-se: Como o enfermeiro pode atuar, tendo como base os pressupostos de sua profissão, no cuidado a mulheres vítimas de violência sexual?

\section{MÉTODOS}

Trata-se de uma pesquisa descritiva, exploratório, de cunho qualitativo do tipo revisão integrativa de literatura. As bibliotecas virtuais a serem utilizadas foram a Biblioteca Virtual em Saúde (BVS), Scientific Electronic Library Online (SCIELO), Diretório de Políticas Editoriais das Revistas Científicas Brasileiras (DIADORIM) e Índice Latino-americano de Publicações Científicas Seriadas (LATINDEX), com os seguintes descritores: "saúde da mulher", "violência contra a mulher", "delitos sexuais", "cuidado de enfermagem", de acordo com o Portal DeCS (Descritores em Ciência da Saúde).

Os critérios de elegibilidade forão: artigos completos, disponíveis gratuitamente em Português e Inglês, publicados nos últimos 10 anos (2010 a 2019) e que respondessem à questão de pesquisa inialmente elecanda.

Quanto aos critérios de inegibilidade, definiu-se os seguintes: artigos em formato de resumo, monografias, dissertações de mestrado e teses de doutorado. Os aspectos da elegibilidade do estudo estão didaticamente descritos na Figura 1.

Com relação aos critérios éticos foi seguido as normativas da boa conduta em pesquisa, livre de plágios e de acordo com a portaria 466/2010. 
Figura 1- Fluxograma dos artigos selecionados para a revisão.
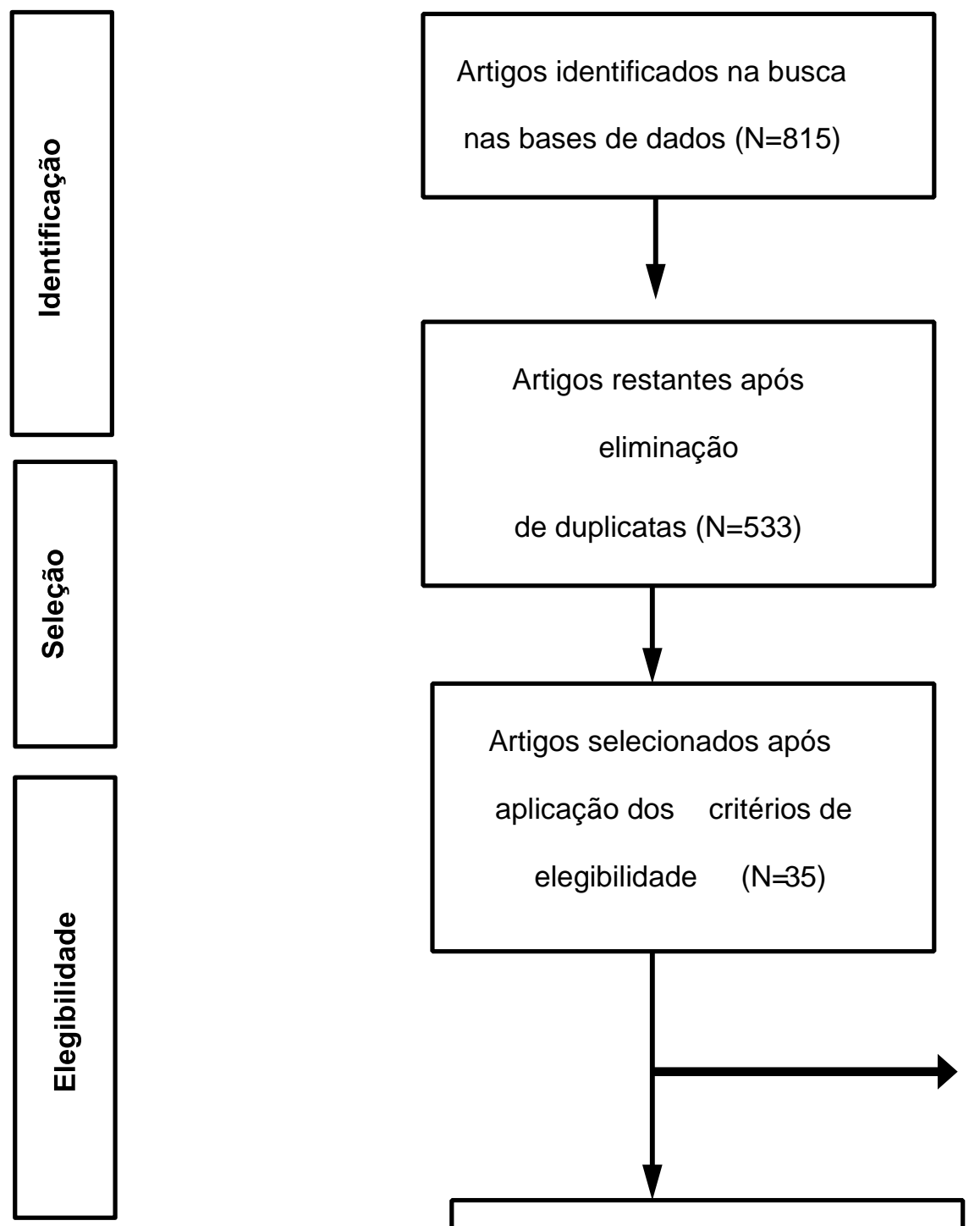

Artigos restantes após eliminação

de duplicatas $(\mathrm{N}=533)$

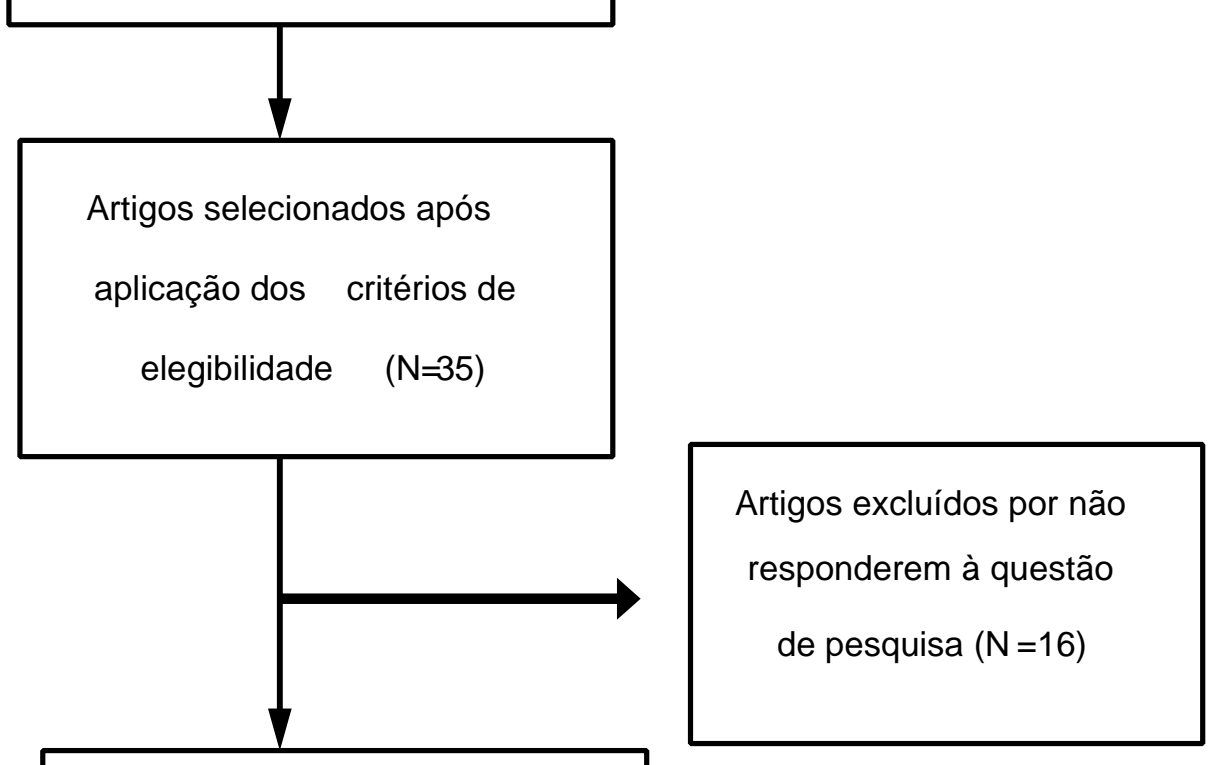

Artigos elegíveis $(\mathrm{N}=19)$
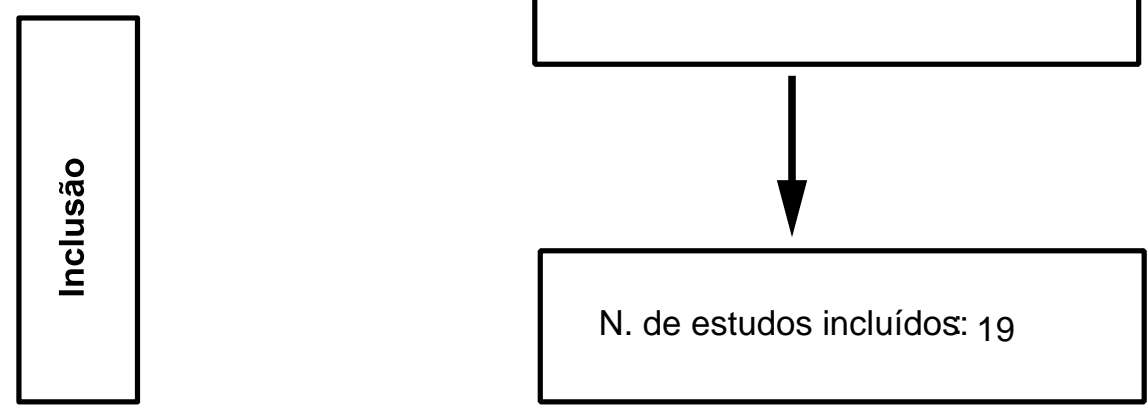

Fonte: Rodrigues JBS, et al., 2020.

Com relação aos critérios éticos foi seguido as normativas da boa conduta em pesquisa, livre de plágios e de acordo com a portaria 466/2010.

\section{RESULTADOS}

Para o presente estudo foram selecionados 19 artigos, obedecendo dos critérios de elegibilidade e inelegibilidade a pesquisa proposta (Quadro 1). 
Quadro 1 - Identificação dos resultados selecionados.

\begin{tabular}{|c|c|c|c|c|c|c|}
\hline № & Plataforma & Idioma & Título & Autor (es) & Ano & Resultados \\
\hline 1 & SCIELO & Português & $\begin{array}{l}\text { A violência contra } \\
\text { mulher numa } \\
\text { perspectiva } \\
\text { histórica uma } \\
\text { questão de gênero }\end{array}$ & $\begin{array}{l}\text { Purificação } \\
\text { MM, et al. }\end{array}$ & 2017 & $\begin{array}{l}\text { O estudo mostrou a violência como um fenômeno social, dando-se ênfase à } \\
\text { violência contra mulheres. Uma rápida viagem na história percebe-se o lugar de } \\
\text { homens e mulheres na sociedade antiga a partir de duas esferas: pólis e casa. } \\
\text { A diferenciação das competências e dos papeis de homens e mulheres no âmbito } \\
\text { da casa e na dimensão publica era orientada e organizada conforme o gênero, } \\
\text { ficando mais evidente qual era o papel que a mulher desempenhava e de como } \\
\text { seu papel era restrito aos mais diversos recursos públicos. }\end{array}$ \\
\hline 2 & LATINDEX & Português & $\begin{array}{l}\text { A violência contra a } \\
\text { mulher: herança } \\
\text { histórica e reflexo } \\
\text { das influências } \\
\text { culturais e } \\
\text { religiosas }\end{array}$ & $\begin{array}{l}\text { Leite RM e } \\
\text { Noronha RML. }\end{array}$ & 2015 & $\begin{array}{l}\text { No trabalho, busca-se mostrar, por meio de uma abordagem histórica, os fatores } \\
\text { determinantes de contribuição para a violência doméstica e sexual contra a } \\
\text { mulher. Procurou-se dissertar como as influências culturais e religiosas } \\
\text { concorrem para a discriminação da figura da mulher num contexto social } \\
\text { agravando a sua situação enquanto vítima das variadas formas de violência. }\end{array}$ \\
\hline 3 & SCIELO & Português & $\begin{array}{l}\text { Violência sexual } \\
\text { contra mulheres no } \\
\text { Brasil: } \\
\text { conquistas } \\
\text { desafios do setor } \\
\text { saúde na década } \\
\text { de } 2000\end{array}$ & $\begin{array}{c}\text { Lima CA e } \\
\text { Deslandes } \\
\text { SF. }\end{array}$ & 2014 & $\begin{array}{l}\text { O artigo faz uma análise e reflexões sobre as principais políticas e ações públicas } \\
\text { produzidas ou instituídas no setor saúde brasileiro ao longo da década de } 2000 \\
\text { e que contribuíram para o enfrentamento da violência sexual contra mulheres no } \\
\text { Brasil, considerando os avanços e as dificuldades encontradas. Apresenta os } \\
\text { conceitos gerais sobre a violência sexual contra a mulher, suas raízes históricas } \\
\text { e seus determinantes sociais e culturais. }\end{array}$ \\
\hline 4 & SCIELO & Português & $\begin{array}{lr}\text { O cuidar em } \\
\text { enfermagem } & \text { à } \\
\text { mulher vítima } & \text { de } \\
\text { violência sexual }\end{array}$ & $\begin{array}{c}\text { Morais SCRV, } \\
\text { et al. }\end{array}$ & 2010 & $\begin{array}{l}\text { A partir deste estudo, aponta-se que o cuidar realizado pela enfermagem à vítima } \\
\text { de violência sexual, ainda é centrado no modelo tecnicista e que esse cuidar } \\
\text { deve ser ampliado para uma ação acolhedora e humana, possibilitando uma } \\
\text { relação de partilha de valores e emoções entre o ser cuidador e o ser cuidado, } \\
\text { com uma atenção que transcenda o sentido de curar e tratar, contemplando com } \\
\text { atitudes de solicitude, paciência e preocupação. Os autores abordam conceitos } \\
\text { fundamentais sobre a violência sexual e o cuidado de enfermagem a partir de } \\
\text { uma abordagem técnica, de acolhimento e da existência humana, pautada em } \\
\text { conceitos filosóficos e de estudiosas da área de enfermagem. }\end{array}$ \\
\hline
\end{tabular}




\begin{tabular}{|c|c|c|c|c|c|c|}
\hline № & Plataforma & Idioma & Título & Autor (es) & Ano & Resultados \\
\hline 5 & DIADORIM & Português & $\begin{array}{l}\text { Violência Contra a } \\
\text { Mulher: Perfil dos } \\
\text { Envolvidos em } \\
\text { Boletins de } \\
\text { Ocorrência da Lei } \\
\text { Maria da Penha }\end{array}$ & $\begin{array}{c}\text { Griebler CN e } \\
\text { Borges JL. }\end{array}$ & 2013 & $\begin{array}{l}\text { O estudo procura mostrar a evolução teórico-conceitual da violência contra a } \\
\text { mulher, em especial a violência sexual, mostrando como a mesma manteve-se } \\
\text { invisível por décadas e como o seu conceito se perpassa nas relações sociais. } \\
\text { O estudo também verificou, a partir, dos dados empíricos que entre os tipos de } \\
\text { violência mais registrados tem-se: a violência psicológica ( }(86,5 \%) \text { e a violência } \\
\text { física }(44,2 \%) \text {. Em relação ao perfil do homem, a idade média foi de } 38,8 \text { anos } \\
\text { (DP }=11,0) \text {, sendo que a maioria tem Ensino Fundamental Completo }(48,1 \%) \text {. } \\
\text { uso de substância, em especial o álcool, por parte dos homens em situação de } \\
\text { agressão, esteve associado em } 39,4 \% \text { dos casos. Os resultados encontrados } \\
\text { nesta pesquisa podem fornecer subsídios para uma maior compreensão do perfil } \\
\text { dos envolvidos na violência contra a mulher. }\end{array}$ \\
\hline 6 & SCIELO & Português & $\begin{array}{l}\text { Vivências de } \\
\text { enfermeiros na } \\
\text { assistência à } \\
\text { mulher } \\
\text { vítima de violência } \\
\text { sexual }\end{array}$ & Reis MJ, et al. & $2010 a$ & $\begin{array}{l}\text { Os resultados mostraram que os enfermeiros percebem o acolhimento como } \\
\text { fundamental na assistência humanizada e no estabelecimento de vínculo com a } \\
\text { cliente. Foram relatados sentimentos como medo, insegurança, impotência, } \\
\text { ambivalência, angústia e ansiedade, que acarretam alterações de } \\
\text { comportamento e interferem na vida pessoal, como também sentimentos de } \\
\text { satisfação e realização profissionais. A capacitação técnica e atividades que } \\
\text { visam o apoio psicológico foram citadas como estratégias que podem ajudar } \\
\text { nesse tipo de atendimento. }\end{array}$ \\
\hline 7 & SCIELO & Português & $\begin{array}{lr}\text { Atendimento de } & \text { à } \\
\text { enfermagem } & \text { às } \\
\text { mulheres } & \text { que } \\
\text { sofrem violência } \\
\text { sexual }\end{array}$ & Reis MJ, et al. & $2010 b$ & $\begin{array}{l}\text { Os resultados mostraram que a maioria dos atendimentos ocorreu durante o } \\
\text { período diurno, houve coerência entre as intervenções e os diagnósticos de } \\
\text { enfermagem identificados, e as mulheres relataram que receberam orientações } \\
\text { de acordo com o protocolo do programa. O tempo da consulta de enfermagem } \\
\text { foi maior no período noturno ( } p=0,0227 \text { ) e essas mulheres mais frequentemente } \\
\text { conheciam os riscos de saúde, decorrentes da violência sexual ( } p=0,0072 \text {, } \\
\text { adequaram os horários do antirretrovirais, de acordo com suas atividades diárias } \\
\text { ( } p=0,0397 \text { ), e estavam mais orientadas quanto à finalidade das sorologias } \\
(p=0,0351 \text { ), evidenciando um cuidado correto. }\end{array}$ \\
\hline
\end{tabular}




\begin{tabular}{|c|c|c|c|c|c|c|}
\hline № & Plataforma & Idioma & Título & Autor (es) & Ano & Resultados \\
\hline 8 & LATINDEX & Português & $\begin{array}{l}\text { Conceitos, causas e } \\
\text { repercussões da } \\
\text { violência sexual } \\
\text { contra a mulher na } \\
\text { ótica } \\
\text { profissionais de } \\
\text { saúde }\end{array}$ & $\begin{array}{l}\text { Bezerra JF, et } \\
\text { al. }\end{array}$ & 2016 & $\begin{array}{l}\text { Entre os sentidos atribuídos ao conceito de violência sexual, destacam-se a } \\
\text { violação dos direitos humanos e ênfase na perpetuação das questões de gênero; } \\
\text { quanto às causas, sobressaiu o machismo, a existência de patologias do } \\
\text { agressor e a reprodução da violência familiar - as repercussões atingem } \\
\text { aspectos psicológicos, além da exposição a doenças e agressões físicas. O } \\
\text { estudo possibilitou a análise dos sentidos atribuídos à violência sexual pela ótica } \\
\text { dos profissionais de saúde investigados, que divergiram sobre a desigualdade } \\
\text { de gênero e contexto social, cujas causas foram apontadas como sendo a cultura } \\
\text { machista, a falta de informação das mulheres sobre os seus direitos e as } \\
\text { questões sociais. Observou-se a dificuldade dos profissionais em trabalhar com } \\
\text { o tema. }\end{array}$ \\
\hline 9 & SCIELO & Português & $\begin{array}{l}\text { Violência sexual: } \\
\text { estudo descritivo } \\
\text { sobre as } \\
\text { vítimas e r o } \\
\text { atendimento em um } \\
\text { serviço } \\
\text { universitário de } \\
\text { referência } \\
\text { Estado de } \\
\text { São Paulo, Brasil }\end{array}$ & $\begin{array}{c}\text { Facuri } \mathrm{CO} \text {, et } \\
\text { al. }\end{array}$ & 2013 & $\begin{array}{l}\text { Os autores realizaram um inquérito epidemiológico para identificar as principais } \\
\text { características da violência sexual contra a mulher. Os dados mostraram que a } \\
\text { maioria das vítimas é branca, solteira, sem filhos, com idade média de } 23,7 \text { anos, } \\
\text { escolaridade entre fundamental e média, empregadas, com religião e prática } \\
\text { religiosa. Um quarto sem relação sexual anterior. Violência sexual principalmente } \\
\text { à noite, na rua, por agressor desconhecido e único, via vaginal e com } \\
\text { intimidação. A maioria contou para outras pessoas e se sentiu apoiada. } \\
\text { Atendimento precoce para quase } 90 \% \text { das mulheres, instaurando medidas } \\
\text { profiláticas. }\end{array}$ \\
\hline 10 & SCIELO & Português & $\begin{array}{l}\text { Planejamento } \\
\text { familiar em Unidade } \\
\text { de Saúde da } \\
\text { Família }\end{array}$ & $\begin{array}{l}\text { Pierre LAS e } \\
\text { Clápis MJ. }\end{array}$ & 2010 & $\begin{array}{l}\text { Os autores realizam reflexões importantes, a partir do planejamento familiar, } \\
\text { como o conceito de gênero evoluiu ao longo do tempo e tem sido a base para o } \\
\text { aprofundamento das relações sociais desiguais entre homens e mulheres e } \\
\text { como este fenômeno contribui para o aprofundamento da violência de gênero. }\end{array}$ \\
\hline
\end{tabular}




\begin{tabular}{|c|c|c|c|c|c|c|}
\hline № & Plataforma & Idioma & Título & Autor (es) & Ano & Resultados \\
\hline 11 & DIADORIM & Português & $\begin{array}{lr}\text { O papel } & \text { da } \\
\text { enfermagem na } & \text { na } \\
\text { violência } & \text { sexual } \\
\text { contra a } & \\
\text { Mulher }\end{array}$ & $\begin{array}{c}\text { Souza CN, et } \\
\text { al. }\end{array}$ & 2019 & $\begin{array}{l}\text { O atendimento às vítimas de violência sexual inclui medidas de prevenção e } \\
\text { tratamento, proporcionando à paciente a garantia de receber cuidado } \\
\text { humanizado e seguro prestado pelo profissional de enfermagem que se encontra } \\
\text { a frente do atendimento a essas mulheres que sofrem esse tipo de violência. O } \\
\text { acolhimento a essas mulheres inclui medidas de prevenção e terapêutica. A } \\
\text { realização de uma boa entrevista acompanhada de um exame físico } \\
\text { céfalopodálico completo pode identificar as lesões e incentivar à paciente a } \\
\text { relatar como ocorreu o caso. }\end{array}$ \\
\hline 12 & DIADORIM & Português & $\begin{array}{l}\text { O enfermeiro e a } \\
\text { violência sexual } \\
\text { contra a } \\
\text { mulher }\end{array}$ & $\begin{array}{c}\text { Souza ACD, et } \\
\text { al. }\end{array}$ & $2017 a$ & $\begin{array}{l}\text { O estudo mostrou que os enfermeiros entendem o conceito de violência sexual } \\
\text { nas seguintes dimensões: estupro, tentativa de estupro, atentado violento ao } \\
\text { pudor, sedução, atos obscenos e assédio que podem ocorrer de forma } \\
\text { conjugada, inclusive com outros tipos de violência física; gestos obscenos e o } \\
\text { assédio do conceito; ato de penetração nos órgãos genitais sem consentimento. } \\
\text { Em relação às ações e condutas, apenas } 50 \% \text { dos enfermeiros relataram realizar } \\
\text { a notificação dos casos, os profissionais relataram não existir um protocolo } \\
\text { definido para as condutas diante dos casos, o que fragiliza a tomada de condutas } \\
\text { e deixa estes profissionais sem as competências necessárias para atuar. }\end{array}$ \\
\hline 13 & DIADORIM & Português & $\begin{array}{l}\text { O enfermeiro e a } \\
\text { preservação de } \\
\text { vestígios nos casos } \\
\text { de violência sexual }\end{array}$ & $\begin{array}{c}\text { Souza ACD, et } \\
\text { al. }\end{array}$ & $2017 b$ & $\begin{array}{l}\text { Os resultados evidenciam que os enfermeiros atuantes no serviço de emergência } \\
\text { no local do estudo, embora considere importante a preservação e coleta de } \\
\text { vestígios frente ao atendimento à mulher vítima de violência sexual, não se } \\
\text { sentem preparados técnicos e cientificamente para desempenha-los. Os dados } \\
\text { permitem também a discussão acerca das limitações na qualificação profissional } \\
\text { para atuar junto às vítimas, em decorrência de uma abordagem incipiente sobre } \\
\text { esse tema nos cursos de graduação, tanto no aspecto teórico como prático, } \\
\text { somado a falta de treinamento e protocolos nos serviços. }\end{array}$ \\
\hline
\end{tabular}




\begin{tabular}{|c|c|c|c|c|c|c|}
\hline № & Plataforma & Idioma & Título & Autor (es) & Ano & Resultados \\
\hline 14 & SCIELO & Português & $\begin{array}{l}\text { Violência sexual } \\
\text { contra } \\
\text { mulheres: a prática } \\
\text { de enfermeiros }\end{array}$ & $\begin{array}{c}\text { Baptista RS, et } \\
\text { al. }\end{array}$ & 2015 & $\begin{array}{l}\text { Os resultados do estudo em tela mostraram que } 96,3 \% \text { reconheceram a violência } \\
\text { sexual e percebem que é sua atribuição investigá-la; } 22,2 \% \text { dos enfermeiros } \\
\text { questionaram suas pacientes sobre a violência; } 85,1 \% \text { fizeram atendimento de } \\
\text { casos suspeitos e/ou confirmados, e } 15,8 \% \text { utilizaram algum protocolo durante o } \\
\text { atendimento. Apenas } 18,5 \% \text { sentiram-se capacitados para atender os casos de } \\
\text { violência sexual. Os dados mostraram que apesar dos enfermeiros terem uma } \\
\text { percepção positiva em relação à sua atuação no atendimento as vítimas, isto não } \\
\text { traspassa para o contexto prático e, a falta de apoio institucional é o principal } \\
\text { fator associado a esta fragilidade. }\end{array}$ \\
\hline 15 & LATINDEX & Português & $\begin{array}{lr}\text { Percepções } & \text { de } \\
\text { enfermeiros sobre o } \\
\text { atendimento à } \\
\text { vítimas } \\
\text { violência sexual }\end{array}$ & $\begin{array}{l}\text { Perucci M, et } \\
\text { al. }\end{array}$ & 2019 & $\begin{array}{l}\text { As enfermeiras não se sentem confortáveis e preparadas para atender as vítimas } \\
\text { de violência sexual, pois só atuam nesse tipo de atendimento porque o programa } \\
\text { está implantado na instituição e faz parte de suas atribuições profissionais. } \\
\text { Evidenciam-se fragilidades na qualificação e educação permanente dos } \\
\text { profissionais para realizarem esse tipo de atendimento. Desta forma, o estudo } \\
\text { mostra que estes profissionais não acreditam que seu atendimento não se dá de } \\
\text { maneira qualificada e integral, como as vítimas atendidas merecem, fragilizando } \\
\text { a práxis assistencial e a implantação de possíveis protocolos institucionais que } \\
\text { possam fazer parte do contexto de atenção. }\end{array}$ \\
\hline 16 & LATINDEX & Português & $\begin{array}{l}\text { Assistência de } \\
\text { Enfermagem às } \\
\text { mulheres vítimas de } \\
\text { violência: revisão } \\
\text { integrativa }\end{array}$ & $\begin{array}{c}\text { Moura MBP, et } \\
\text { al. }\end{array}$ & 2011 & $\begin{array}{l}\text { Os resultados do estudo abordaram a assistência de enfermagem às mulheres } \\
\text { violentadas e apresentaram cinco tipos diferentes de violência sendo: violência } \\
\text { de gênero, sexual, física, psicológica e doméstica. O estudo mostrou ainda que } \\
\text { os enfermeiros assistenciais articularam o cuidado em consonância com os } \\
\text { demais profissionais e serviços prestados, mantiveram o controle do } \\
\text { gerenciamento das ações, embora, ressaltamos que o principal desempenho foi } \\
\text { o acolhimento às vítimas da violência onde os enfermeiros puderam realizar a } \\
\text { escuta qualificada, à luz da política nacional de humanização. }\end{array}$ \\
\hline
\end{tabular}




\begin{tabular}{|c|c|c|c|c|c|c|}
\hline № & Plataforma & Idioma & Título & Autor (es) & Ano & Resultados \\
\hline 17 & LATINDEX & Português & $\begin{array}{lr}\text { Análise } & \text { da } \\
\text { humanização } & \text { no } \\
\text { acolhimento da } & \\
\text { equipe } & \text { de } \\
\text { enfermagem } & \text { à } \\
\text { mulher vítima } & \text { de } \\
\text { violência sexual }\end{array}$ & $\begin{array}{l}\text { Marques YCB } \\
\text { e Santos CRN. }\end{array}$ & 2011 & $\begin{array}{l}\text { O processo de acolhimento à mulher vítima de violência sexual, segundo o } \\
\text { estudo, é realizado de forma humanizada, holística; A equipe multiprofissional é } \\
\text { valorizada de acordo com a qualidade individual de cada profissional e está } \\
\text { presente em depoimentos, como fator imprescindível no atendimento; A } \\
\text { sensibilização dos profissionais se torna presente quando indagados sobre } \\
\text { emoções que ocorrem durante a consulta; Consequentemente, o apoio } \\
\text { psicológico, fundamental para a saúde psíquica dos profissionais que lidam com } \\
\text { este atendimento; A falta de suporte institucional evidenciada em vários } \\
\text { discursos comprovou-se, uma carência urgente, pois não existe ambiente físico } \\
\text { adequado para a recepção da vítima. Segundo, dados analisados observaram- } \\
\text { se no cuidado de enfermagem e no multiprofissional: a humanização presente } \\
\text { no acolhimento; a sensibilização dos profissionais frente à violência; a } \\
\text { valorização de uma equipe multidisciplinar; a necessidade de um apoio } \\
\text { psicológico para o profissional que atende a usuária; e, a carência de um suporte } \\
\text { físico para acolher a vítima. }\end{array}$ \\
\hline 18 & SCIELO & Português & $\begin{array}{l}\text { Violência contra a } \\
\text { mulher e suas } \\
\text { consequências }\end{array}$ & Netto LA, et al. & 2014 & $\begin{array}{l}\text { Os resultados evidenciam que os episódios de violência sexual comprometem a } \\
\text { conservação da integridade estrutural, pessoal e psicológica da mulher. O estudo } \\
\text { mostrou ainda que a atenção prestada pelo enfermeiro às mulheres em situação } \\
\text { de violência, quanto à conservação de energia, é essencial a anamnese e o } \\
\text { exame físico, com verificação dos sinais vitais, avaliação nutricional relativa à } \\
\text { frequência e à disponibilidade de alimentos, prática de exercícios físicos, padrão } \\
\text { das eliminações vesicointestinais e avaliação dos ciclos menstruais. O enfoque } \\
\text { desses parâmetros foi a identificação de aspectos da conservação e gastos de } \\
\text { energia relativas ao sofrimento, trazendo a mulher para o cuidado do enfermeiro. } \\
\text { As consequências pessoais das participantes da pesquisa foram sentimentos de } \\
\text { aniquilação, tristeza, desânimo, solidão, estresse, baixa autoestima, } \\
\text { incapacidade, impotência, ódio e inutilidade. }\end{array}$ \\
\hline 19 & SCIELO & Português & $\begin{array}{l}\text { Atuação } \quad \text { da } \\
\text { enfermagem frente } \\
\text { à violência sexual } \\
\text { contra crianças e } \\
\text { adolescentes }\end{array}$ & $\begin{array}{l}\text { Silva LMP, et } \\
\text { al. }\end{array}$ & 2011 & $\begin{array}{l}\text { Os dados deste estudo evidenciam o cuidado do enfermeiro à mulher vítima de } \\
\text { violência sexual, com enfoque ao grupo de crianças e adolescentes. Os } \\
\text { resultados evidenciaram desconhecimento dos profissionais sobre os conceitos } \\
\text { fundamentais a respeito do tema e isto, se apresenta com uma das principais } \\
\text { barreiras para a consolidação deste tipo de cuidado. Os achados ainda } \\
\text { confirmam que a atuação dos profissionais de enfermagem neste cenário deve } \\
\text { ser feito à luz da legislação profissional e dos direitos humanos. }\end{array}$ \\
\hline
\end{tabular}

Fonte: Rodrigues JBS, et al., 2020. 


\section{DISCUSSÃO}

\section{Categoria I - Impacto da violência sexual no cotidiano da mulher}

Segundo Bezerra JF, et al. (2016), as lesões físicas constituem-se em uma das principais marcas da violência sexual que as mesmas sofrem. Os autores dissertam que mulheres agredidas sexualmente são lesionadas fisicamente com socos, chutes, que provocam traumas na face, pescoço, costelas, abdômen, traumas nos genitais, que podem provocar sequelas temporárias e/ou permanentes, além da humilhação causada à mesma.

Para Purificação MM (2017), Leite RM e Noronha RML (2015), as agressões físicas fazem parte das bases da violação histórica exercidas pelo homem sobre a mulher consolidam as relações de gênero que se construíram extremamente desiguais com o passar do tempo. A determinação política e social das relações de gênero ao longo do tempo mostra a figura do homem como aquele que possui a força física superior e que deve exercer esta para consolidar o seu papel na sociedade (PIERRE LAS e CLÁPIS MJ, 2010).

Neste contexto, Dourado SM e Noronha CV (2015), dissertam que as agressões físicas no conjunto das violências contra a mulher podem chegar a representar até $63,2 \%$ dos casos e que os traumas corpóreos são muito comuns e podem levar à internação da vítima por estados de gravidade clínica. Além disso, estas lesões podem gerar sentimentos de vergonha e depreciação nas mulheres violentadas, fato que pode atuar como um disparador para os estados de sofrimento psicológico.

Outro impacto da violência sexual explicitado nos estudos diz respeito aos danos psicológicos gerados na vítima, que se associam a eventos como estresse pós-traumático, depressão, psicoses, crises de ansiedade generalizada, síndrome do pânico até mesmo chegando a ideação suicida. Os estudos revelam que os episódios de violência sexual geralmente são acompanhados de intenso estresse psicológico, fato que aprofunda os danos psicológicos na mulher violentada (MOURA MPB, et al., 2011; GRIEBLER CN e BORGES JL, 2013; NETTO LA, et a., 2014; BEZERRA JF, et al., 2016).

Os transtornos mentais podem acometer até $18,7 \%$ das mulheres adultas e incluem episódios de pânico, ansiedade, depressão e ideação suicida. Dentre os fatores associados a estes transtornos, destacam se 0 fato das mulheres terem sofrido algum tipo de violência durante a vida, inclusive a violência sexual. Além disso, essa situação contribui para a diminuição da qualidade de vida das mulheres (SENICATO C, et al., 2018).

A exposição às infecções sexualmente transmissíveis (IST), incluindo o HIV e AIDS constituem outro problema decorrente da violência sexual e vulnerabiliza as mulheres vítimas deste ato. Os autores referem que este impacto deve ser um dos primeiros pontos a serem identificados durante 0 atendimento, visto que podem gerar danos permanentes se não tratados em forma oportuna (GRIEBLER CN e BORGES JL, 2013; BEZERRA JF, et al., 2016).

A violência sexual consumida por ato de penetração vaginal e/ou anal foi estudado por Facuri $\mathrm{CO}$, et al. (2013), como umas das principais formas deste tipo de violência e, reforça que este fato predispõe sobremaneira as vítimas a contraírem alguma IST.

Dados do Ministério da Saúde (MS), mostram que as IST, incluindo o HIV e AIDS são considerados problemas de saúde pública no país, principalmente porque atingem populações social e paradigmaticamente vulnerabilizadas, entre essas populações encontram-se as mulheres vítimas de violência sexual, que respondem por até $88 \%$ de todos os casos de violência sexual no país. As IST podem acarretar desde infecções agudas localizadas, até infecções sistêmicas, potencialmente fatais, sem falar dos danos crônicos que podem acarretar no sistema reprodutor feminino, levando inclusive a esterilização involuntária (BRASIL, 2020).

Os estudos apontam ainda que mulheres violentadas sexualmente, por conta do trauma associado, tendem a desenvolver sentimentos de inaptidão de si própria e com isso, se isolam do convívio social. Isto se 
dá como consequência secundária aos impactos psicológicos, onde a vítima desenvolve tristeza, solidão, baixa autoestima, impotência, incapacidade e ódio (NETTO LA, et al., 2014).

Para Arpini DM, et al. (2012), o isolamento do convívio em sociedade, os sentimentos de medo, incapacidade e retraimento são descritos na literatura como sequelas posteriores ao evento da violência sexual em mulheres, desde a adolescência até a vida adulta e figura como importante complicação na vida dessas mulheres. Por outro lado, Lira MOSC, et al. (2017), apontam que a prostituição e condutas hipersexualizadas podem manifestar-se na vida adulta como consequências do episódio de violência sexual, tornando essas mulheres vulneráveis às IST, por exemplo (BRASIL, 2020).

Por fim, Lima CA e Deslandes SF (2014), apontam que os impactos da violência sexual contra a mulher ainda figuram como um desafio para o estado brasileiro, visto que este fenômeno ainda persiste como fruto das relações desiguais na construção da identidade de gênero. As ações ao longo das últimas duas décadas diminuíram os índices de violência sexual, porém, não o suficiente, sendo necessário o fortalecimento das políticas e programas que visem a prevenção, tratamento das vítimas, enfrentamento do fenômeno e responsabilização dos agressores, pois, somente assim, será possível reduzir o impacto da violência sexual na saúde física, psíquica e social das mulheres. Os autores ainda dissertam que negligenciar esses impactos causados pela violência sexual pode, em médio prazo, impactar em elevados níveis na qualidade de vida das mulheres brasileiras.

\section{Categoria II - Ações do enfermeiro à luz da prática profissional no cuidado às mulheres vítimas de violência sexual}

$\mathrm{O}$ acolhimento configura como o ponto de partida para o agir cuidativo do enfermeiro junto às mulheres vítimas de violência sexual, sendo citado por vários autores como um processo pelo qual os enfermeiros devem fazer escuta qualificada das vítimas, afim de que as mesmas possam sentir-se seguras para o estabelecimento do vínculo, necessário para a efetividade das ações preventivas e terapêuticas, fundamentais para a humanização do atendimento. Além disso, os estudos mostram que os enfermeiros percebem o acolhimento como algo necessário para as práticas de cuidado humanizadas a esta população (MORAIS SCRV, et al., 2010; REIS MJ, et al., 2010a; MOURA MPB, et al., 2011; SOUZA CN, et al., 2019; PERUCCI M, et al., 2019).

Neste contexto, o acolhimento é concebido como parte dos pilares da Política Nacional de Humanização (PNH) e deve envolver profissionais, gestores e usuários em um movimento de garanta acesso dos usuários aos serviços de atenção à saúde, onde a escuta qualificada deve ser feita pelos profissionais com empatia e moldando respostas positivas para que os usuários possam refletir sobre sua condição atual e suas necessidades de saúde, afim de que o mesmo possa ser protagonista nos processos de intervenção para a resolutividade de suas demandas. O acolhimento deve ser transversal no Sistema Único de Saúde (SUS) desde os serviços de atenção primária até a reabilitação dos sujeitos nos mais variados contextos (BRASIL, 2008; COUTINHO LRP, et al., 2015).

Outra dimensão do cuidar em enfermagem à mulher vítima de violência sexual trazida nos estudos é a aplicação de protocolos padronizados no atendimento dessas usuárias, com vistas a identificar e documentar o caso de violência, preservar e coletar os vestígios da violência, encaminhar para realização de exames, terapêutica medicamentosa e orientações pós-atendimento. Estas informações permitem que as demandas trazidas pelas vítimas possam ser atendidas em tempo oportuno, além de gerar confiança na mesma acerca da atenção dispensada. Porém, apesar de terem consciência da importância da ação mediada por protocolos, os enfermeiros relatam deficiências de capacitação para a implantação de tais protocolos no serviço, fazendo com que a adesão aos mesmos seja inferir a 19\% em algumas realidades estudadas (MORAIS SCRV, et al., 2010; REIS MJ, et al., 2010b; BATISTA RS, et al., 2015; SOUZA ACD, et al., 2017a; SOUZA ACD, et al., 2017b; SOUZA CN, et al., 2019).

A utilização de protocolos na atenção às mulheres vítimas de violência sexual no Brasil é preconizada por norma técnica do Ministério da Saúde que orienta as ações em âmbito preventivo e terapêutico, a partir de 
condutas que visem o acolhimento da vítima, documentação do caso e notificação compulsória, profilaxia para infecções virais e não-virais, anticoncepção de emergência, rastreamento laboratorial, além de tratamento das lesões físicas e encaminhamento para acompanhamento psicológico (BRASIL, 2012).

Além disso, Costa ANB, et al. (2018), dissertam que a elaboração e implantação de protocolos assistências tanto na atenção primária, quanto nos hospitais, são fundamentais para padronizar as condutas dos profissionais, além, de promoverem segurança do paciente nos contextos de cuidado.

A aplicação do Processo de Enfermagem (PE) foi relatada ainda como outra ferramenta no atendimento das vítimas de violência sexual. A partir das premissas do PE, os enfermeiros acolhem a vítima, realizando anamnese e exame físico minuciosos, para identificação dos problemas de saúde e de enfermagem, afim de que possam construir um plano de cuidados direcionado e individualizado a cada caso e, desta forma, implementarem as condutas que possam ir ao encontro das particularidades de cada mulher vítima (SILVA LMP, et al., 2011; BATISTA RS, et al., 2015; SOUZA CN, et al., 2019).

O processo de enfermagem faz parte das estratégias para a qualificação do processo de trabalho dos enfermeiros nos diversos contextos assistenciais. Ele deve ser aplicado a partir de uma teoria de enfermagem que melhor se enquadre no contexto onde o cuidado deve acontecer. Estrutura-se em etapas interdependentes e interrelacionadas e é normatizada no Brasil por meio da resolução 358 de 2009 do Conselho Federal de Enfermagem (CONSELHO FEDERAL DE ENFERMAGEM, 2009; BRASIL, 2012).

O PE deve acontecer de maneira sistemática e deliberada em todos os espaços de atenção à saúde. No contexto das mulheres vítimas de violência sexual, a aplicação do PE permite a organização das ações previstas nas normas técnicas do MS para o atendimento dessa população (CONSELHO FEDERAL DE ENFERMAGEM, 2009; BRASIL, 2012).

Segundo Higa R, et al. (2008), a aplicação do PE no atendimento às mulheres vítimas de violência sexual, com definições de diagnósticos de enfermagem claros e metas de assistência exequíveis é fundamental para a construção de um protocolo de cuidados imediatos e tardios, com o correto encaminhamento das vítimas aos outros pontos do cuidado multidisciplinar. Isto faz com que ocorra a humanização do cuidado de enfermagem a estas mulheres, além de garantir o fortalecimento do exercício do profissional do enfermeiro, a medida em que confere a este profissional a autonomia necessária para suas práticas de cuidado.

Uma demanda trazida pelos autores deste estudo diz respeito à necessidade de maior qualificação profissional dos enfermeiros para a atuação frente a mulher vítima de violência sexual, reportando carência nos processos de educação permanente para o fortalecimento das ações destes profissionais (MORAIS SCRV, et al., 2010; REIS MJ, 2010b; BATISTA RS, et al., 2015; SOUZA ACD, et al., 2017a; SOUZA ACD, et al., 2017b; SOUZA CN, et al., 2019).

Após análise da literatura pesquisada é possível perceber o quão complexo é o fenômeno da violência sexual e o quanto o mesmo impacta na vida da mulher em diferentes aspectos, com repercussões diretas para a sociedade, impedindo inclusive, a correção no desenvolvimento das relações de gênero, afim de corrigir as desigualdades existentes entre essas.

\section{CONSIDERAÇÕES FINAIS}

O presente estudo constatou que a violência sexual contra a mulher é um problema universal e fortemente presente do país, com uma parte muito importante ainda invisível devido aos altos índices de subnotificação. O problema tem como uma de suas principais causas o aprofundamento nas desigualdades nas relações de gênero e causa danos físicos e psicológicos para as vítimas, com repercussões para toda a sociedade. Percebeu-se ainda que o cuidado da equipe de enfermagem, em especial dos enfermeiros, é pautado nas competências inerentes à formação destes profissionais. Como fragilidades no processo do cuidado, identificou-se a falta de formação permanente nos serviços sobre a problemática, a ausência de protocolos de cuidados e a falta de apoio institucional tanto para a saúde mental dos profissionais, como a adequação 
dos espaços físicos para uma assistência resolutiva. Portanto, pode-se concluir, a partir deste estudo, que o cuidado de enfermagem à mulher vítima de violência sexual é, de modo geral, adequado, com atitudes acolhedoras e humanizadas, podendo ser melhorado, a partir de articulações intersetoriais que visem a prevenção, o tratamento e a notificação adequada dos casos.

\section{REFERÊNCIAS}

1. ARPINI DM, et al. Trauma psíquico y abuso sexual: la visión de niñas en situación de vulnerabilidad. Psicologia: teoria e prática, 2012; 14(2): 88-101.

2. BATISTA RS, et al. Violência sexual contra mulheres: a prática de enfermeiros. Revista da Rede de Enfermagem do Nordeste, 2015; 16(2): 210-217.

3. BEZERRA JF, et al. Conceitos, causas e repercussões da violência sexual contra a mulher na ótica de profissionais de saúde. Revista Brasileira em Promoção da Saúde, 2016; 29(1): 51-59.

4. BRASIL. Ministério da Saúde. Secretaria de Atenção à Saúde. Departamento de Ações Programáticas Estratégicas. Prevenção e tratamento dos agravos resultantes da violência sexual contra mulheres e adolescentes: norma técnica (3a ed.). Brasília, DF: Ministério da Saúde, 2012.

5. BRASIL. Ministério da Saúde. Núcleo Técnico da Política Nacional de Humanização. Política Nacional de HumanizaçãoHumanizaSUS. Documento Base para Gestores e Trabalhadores do SUS (3 ed.), Brasília, DF: Ministério da Saúde, 2008.

6. BRASIL. Ministério da Saúde. Secretaria de Vigilância em Saúde. Protocolo Clínico e Diretrizes Terapêuticas para Atenção Integral às Pessoas com Infecções Sexualmente Transmissíveis (IST). Brasília, DF: Ministério da Saúde, 2020.

7. CECCON RF, MENEGHEL SN. Iniquidades de gênero: mulheres com hiv/aids em situação de violência. Physis: Revista de Saúde Coletiva, 2017; 27(4): 1087-1103.

8. CONSELHO FEDERAL DE ENFERMAGEM. Resolução COFEN 358 de 15 de outubro de 2009. Dispõe sobre a Sistematização da Assistência de Enfermagem e a implementação do Processo de Enfermagem em ambientes, públicos ou privados, em que ocorre o cuidado profissional de Enfermagem, e dá outras providências. Brasília, DF, 2009.

9. COSTA ANB, et al. Elaboração de protocolos assistenciais à saúde como estratégia para promover a segurança do paciente. Revista Brasileira de Educação e Saúde, 2018; 8(1): 25-30.

10. COUTINHO LRP, et al. Acolhimento na Atenção Primária à Saúde: revisão integrativa. Saúde em debate, 2015; 39(35): 514524.

11. DOURADO SM, NORONHA CV. Marcas visíveis e invisíveis: danos ao rosto feminino em episódios de violência conjugal. Ciência \& Saúde Coletiva, 2015; 20(9): 2911-2920.

12. FACURI CO, et al. Violência sexual: estudo descritivo sobre as vítimas e o atendimento em um serviço universitário de referência no estado de São Paulo, Brasil. Cadernos de Saúde Pública, 2013; 29(5): 889-898.

13. GARCIA LP. A magnitude invisível da violência contra a mulher. Epidemiologia e Serviços de Saúde, 2016; 25(3): $451-454$.

14. GRIEBLER CN, BORGES JL. Violência contra a mulher: perfil dos envolvidos em boletins de ocorrência da Lei Maria da Penha. Psico, 2013; 44(2): 7.

15. HIGA R, et al. Atendimento à mulher vítima de violência sexual: protocolo de assistência de enfermagem. Revista da Escola de Enfermagem da USP, 2008;42(2): 377-382.

16. LEITE RM, NORONHA RML. A violência contra a mulher: herança histórica e reflexo das influências culturais e religiosas. Revista Direito \& Dialogicidade, 2015; 6(1): 1-15.

17. LIMA CA, DESLANDES SF. Violência sexual contra mulheres no Brasil: conquistas e desafios do setor saúde na década de 2000. Saúde e Sociedade, 2014; 23(3): 787-800.

18. LIRA MOSC, et al. Abuso sexual na infância e suas repercussões na vida adulta. Texto \& Contexto Enfermagem, 2017; 26(3): 1-8.

19. MACHADO CL, et al. Gravidez após violência sexual: vivências de mulheres em busca da interrupção legal. Cadernos de Saúde Pública, 2015; 31(2): 345-353.

20. MORAIS SCRV. O cuidar em enfermagem à mulher vítima de violência sexual. Texto \& Contexto - Enfermagem, 2010; 19(1): 155-160.

21. MOURA MPB. Assistência de Enfermagem às mulheres vítimas de violência: revisão integrativa. Revista de Enfermagem do Centro-Oeste Mineiro, 2011; 1(4): 571-582.

22. NETTO LA, et al. Violência contra a mulher e suas consequências. Acta paulista de enfermagem, 2014; $27(5): 458-464$.

23. NUNES MCA, et al. Violência Sexual contra Mulheres: um estudo comparativo entre vítimas adolescentes e adultas. Psicologia: Ciência e Profissão, 2017; 37(4): 956-969.

24. PERUCCI M, et al. Percepções de enfermeiros sobre o atendimento às vítimas de violência sexual. Enfermagem Revista, 2019; 22(1): 68-78.

25. PIERRE LAS, CLAPIS MJ. Family planning in a family health unit. Revista latino-americana de enfermagem, 2010; 18(6): 1161-1168.

26. PURIFICAÇÃO MM, et al. A violência contra mulher numa perspectiva histórica-uma questão de gênero. Ciência \& Desenvolvimento-Revista Eletrônica da FAINOR, 2017; 10(3).

27. REIS MJ, et al. Atendimento de enfermagem às mulheres que sofrem violência sexual. Revista LatinoAmericana de Enfermagem, 2010b; 18(4): 740-747.

28. REIS MJ, et al. Vivências de enfermeiros na assistência à mulher vítima de violência sexual. Revista de Saúde Pública, 2010a; 44: 325-331.

29. SENICATO C, et al. Transtorno mental comum em mulheres adultas: identificando os segmentos mais vulneráveis. Ciência \& Saúde Coletiva, 2018; 23(8): 2543-2554.

30. SILVA LMP, et al. Atuação da enfermagem frente à violência sexual contra crianças e adolescentes. Revista Brasileira de Enfermagem, 2011; 64(5): 919-924.

31. SOUZA ACD, et al. O enfermeiro e a violência sexual contra a mulher. International Nursing, 2017a; 9(2): 1-5. 
32. SOUZA ACD, et al. O enfermeiro e a preservação de vestígios nos casos de violência sexual. International Nursing, 2017b; $9(2): 1-4$

33. SOUZA CS. Caracterização da Violência Sexual em Mulheres na cidade de Ribeirão Preto, SP. Dissertação (Mestrado em Ciências Médicas) - Departamento de Medicina Social. Universidade de São Paulo, Ribeirão Preto, 2012.

34. SOUZA CN, et al. O papel da enfermagem na violência sexual contra a mulher. Revista Brasileira Interdisciplinar de Saúde, 2019; 1(4): 31-36.

35. SOUZA ML, et al. O Cuidado em Enfermagem: uma aproximação teórica. Texto \& Contexto - Enfermagem, 2005; 14(2): 266-270. 